\title{
DUST MONITORING EXPOSURE: ABRASIVE BLASTING PROCESS
}

\author{
Hanis Zakaria ${ }^{\# 1}$, Norzelawati Asmuin ${ }^{\# 2}$, Muhamad Nurmizan Ahmad \#³ , Norhalim Hassan $*^{4}$, \\ Mohamad Farid Sies $\# 5$ \\ ${ }^{\#}$ Faculty of Mechanical Engineering \& Manufacturing \\ Universiti Tun Hussein Onn Malaysia, 86400 Parit Raja, Johor, Malaysia \\ 1'hanisz@uthm.edu.my \\ 2norzela@uthm.edu.my \\ *Department of Occupational Safety and Health Malaysia, Ministry of Human Resource, Malaysia \\ 4norhalim@mohr.gov.my
}

\begin{abstract}
Abrasive blasting is a process that is widely used to clean and remove the coating on a surface by using a variety of media. In Malaysia, blasting process subjected under the Occupational Safety and Health (Use and Standard of Exposure to Chemical Hazardous to Health) Regulations 2000 (USECHH 2000), and Factories and Machinery (Mineral Dust) Regulations 1989. This study was done to find out the concentration and composition of dust during blasting process. The blasting process was conducted about eight hours which used two types of media; aluminium oxide and steel shot. Two methods were used to collect dust from blasting process; NIOSH 0600 (respirable dust) and NIOSH 0500 (inhalable dust). There are three types of exposure that have been analysed; standard exposure, zero exposure and similar exposure for determination of PEL. The analysis result of dust concentration for aluminium and steel shot, most of the analysis shows that the level of exposure has exceeded the permissible exposure limits that have been allowed in the USECHH 2000. In the standard exposure analysis the result show dust concentration exceed three times PEL for steel shot. The Energy Dispersive X-ray Spectrometry (EDS) result shows the presence of several elements that are harmful to health such as silica (Si) and lead (Pb).
\end{abstract}

Keywords: Abrasive Blasting, Aluminium Oxide, Steel Shot, Occupational Safety and Health.

\section{INTRODUCTION}

Abrasive blasting is a process that is widely used to clean and remove a coating on a surface by using abrasive media such as aluminium oxide, steel shot, garnet and coal slag. The process can produce a lot of dust concentration due to abrasive material, removal of old paint, and corrosive material on a surface. A fraction by weight of used abrasive escapes into the atmosphere as particulate matter [1]. The abrasive media from the blasting process contain of chemical substance where it can be harmful to our health, for example, the usage of sand media that containing chemical element silica dioxide $\left(\mathrm{SiO}_{2}\right)$ can cause a person to suffer lung cancer, silicosis and respiratory problems [2]. Garment industry in Turkey, china and Bangladesh were used silica sand as a media in blasting process where the purpose of these blasting is to produce jeans that 'worn out' look. Almost half of the 200 million pairs of jeans exported from Bangladesh each year are sandblasted [3]. The exposure of silica sand can expose workers to serious health problems and can cause death within a few months or years [3]. The silica sand contains crystalline silica (crystalline silica) where people who inhale these particles may be suffered silicosis and respiratory problems [4].

The purpose of this study is to determine the significance level of health effect to workers/operator from the abrasive blasting process. Occupational Safety and Health (Use and Standard of Exposure to Chemical Hazardous to Health) Regulations 2000 (USECHH 2000) was used as main standard reference [5].

\section{LITERATURE REVIEW}

Abrasive blasting is a process of moving the flow of abrasive material at high speed towards a surface using compressed air, fluid and centrifugal wheel. Abrasive blasting is widely used in various industries such as ship building, automotive, canning plants, gas transmission stations, etc. There are several types of media used in blasting process such as silica sand, garnet, steel grit and aluminium oxide. Steel grit and aluminium oxide are usually used in a blast room or blast cabinet where the media is re-usable [1].

The purpose of blasting process is to clean a surface such as iron, steel, stone, aluminium, copper, glass and plastic. The blasting process can be done whether in open area and closed area. The blasting activity at open area is done on a large surface such as cleaning on bridge and ship while close area is done in an enclosed area like closed room or using blasting cabinet [6]. There have five types of blasting cleaning system which are portable blasting machine, blast room, blast cabinet, automatic blast machine and wet blast machine [7].

Dust concentration from abrasive blasting process can be divided into two categories which are inhalable dust and respirable dust. The inhalable dust can be inhaled by workers or people surrounding where it can trap in the respiratory system. While respirable dust can penetrate the lungs easily to the bottom of the bronchial and 
alveolar regions [8]. Besides that, inhalable dust and respirable dust have a permissible exposure limit where this limit depends on the type of media used in the blasting process. These exposure limits were listed in Occupational Safety and Health (Use and Standards of Exposure to Chemicals Hazardous to Health) Regulations 2000.

Dust from the blasting process can give negative effect toward worker's health and people surrounding. The exposure of aluminium oxide dust can irritate the skin, eye, nose and throat. Prolonged exposure to the workers would lead to lung damage [9].

Hazard from blasting process can be controlled by using less hazardous abrasive media. Besides that, use of suitable personal protective equipment (PPE) such as goggle, glove, mask N95 and blasting helmet with external air supply can reduce risk during blasting process.

\section{EXPERIMENTAL SETUP}

Two types of media were used to remove the old paint on the tank surface such as aluminium oxide and steel shot. Compressor was used to supply compressed air of 4-7 bar to the portable blasting machine through the compressor hose. Blasting hose was used to control the direction of the media during blasting process.

The sampling process was conducted during blasting activity where two methods were used to collect the dust concentration such as NIOSH 0500 (inhalable dust) [10] and NIOSH 0600 (respirable dust) [11]. The air flow rate for respirable pump was $1.7 \mathrm{~L} / \mathrm{min}$ while for inhalable pump and maximum exposure limit (MEL) pump were $2.0 \mathrm{~L} / \mathrm{min}$. The sampling pump was used together with cassette and tube.

Blasting process was run for 4 hours and 4 hours resting time. The weighing process was carried out by using microbalance. The composition of dust concentration was observed using Energy Dispersive X-ray Spectrometry (EDS). In EDS testing, each sample was test three (3) times. This method is to determine the elements are present in samples. The sample placed under vacuum and excited to higher energy state with an electron beam.

Table 1 show the permissible exposure limit (PEL) stated in USECHH 2000 Regulations as the reference.

Table 1: Permissible exposure limit (PEL)

\begin{tabular}{|l|c|c|}
\hline \multirow{2}{*}{ Type of Dust } & Inhalable & Respirable \\
\cline { 2 - 3 } & $\mathbf{m g} / \mathbf{m}^{\mathbf{3}}$ & $\mathbf{m g} / \mathbf{m}^{\mathbf{3}}$ \\
\hline Aluminium oxide & 10 & 10 \\
\hline Steel shot & 5 & 5 \\
\hline PNOC & 10 & 3 \\
\hline
\end{tabular}

\section{RESULT AND DISCUSSION}

In this study, there are three kind of analysis has been used as the reference; aluminium oxide limit, steel shot limit and particulate not otherwise classified (PNOC). These three analyses have been used because the compositions of the media are not really fixed.

Three type of calculation used to analyse the total of dust collect during the process; total dust, similar exposure and zero exposure. These three kinds of calculation were use because the blasting process is less than 8 hours.

Referring to USECHH 2000 regulations, Table 1 demonstrated the PEL for three types of dust; aluminium oxide, steel shot and PNOC. Each of dust can be divided into two categories such as inhalable dust and respirable dust.

\section{A. Aluminium oxide media}

Table 2 shows the time weight average result of dust concentration of aluminium oxide derived from blasting process. The data was divided into two analyses which are inhalable dust and respirable dust. There are three types of exposures such as standard exposure, zero exposure and similar exposure for each analysis. Every exposure was compared to the exposure limit such as aluminium oxide exposure limit and Particulate Not Otherwise Classified (PNOC) exposure limit that have been allowed in the USECHH 2000 regulations. Based on the result, the value of inhalable dust was $31 \mathrm{mg} / \mathrm{m}^{3}, 24.5 \mathrm{mg} / \mathrm{m}^{3}$ and $98 \mathrm{mg} / \mathrm{m}^{3}$. For respirable the value of dust concentration was $16.5 \mathrm{mg} / \mathrm{m}^{3}, 10.5 \mathrm{mg} / \mathrm{m}^{3}$ and $42 \mathrm{mg} / \mathrm{m}^{3}$. After the comparison of exposure limit, all result shows that the dust concentration was exceeded the entire permissible exposure limit (PEL) in table 1. 
Table 2: TWA 8-hours for aluminium oxide media

\begin{tabular}{|c|c|c|}
\hline \multirow{2}{*}{$\begin{array}{l}\text { Type of } \\
\text { Exposure }\end{array}$} & Inhalable & Respirable \\
\hline & $\mathrm{mg} / \mathrm{m}^{3}$ & $\mathrm{mg} / \mathrm{m}^{3}$ \\
\hline Standard exposure & 31 & 16.5 \\
\hline Zero exposure & 24.5 & 10.5 \\
\hline Similar exposure & 98 & 42 \\
\hline
\end{tabular}

The similar exposure limit shows the higher value of dust concentration compared to zero exposure and standard exposure. Similar exposure is the assumption of workers will be exposed with the same environment during resting time. While zero exposure means the workers are not exposed to any hazardous dust during resting with the assumption workers will get the fresh air.

For this study, the dust collect from the experiment show that during blasting process show the dust collect is very significance to the workers. The dust release from the abrasive blasting process can affect the health of workers in the absence of adequate control measure. While during resting time the sampler still record some amount of dust about $6.5 \mathrm{mg} / \mathrm{m}^{3}$ for four hours for inhalable dust and $6 \mathrm{mg} / \mathrm{m}^{3}$ for fours for respirable dust.

B. Steel shot media

Table 3: TWA 8-hours for steel shot media

\begin{tabular}{|l|r|r|}
\hline \multirow{2}{*}{ Type of Exposure } & \multicolumn{1}{|c|}{ Inhalable } & \multicolumn{1}{|c|}{ Respirable } \\
\cline { 2 - 3 } & \multicolumn{1}{|c|}{$\mathbf{~ m g / \mathbf { m } ^ { 3 }}$} & \multicolumn{1}{|c|}{$\mathbf{~ m g / \mathbf { m } ^ { \mathbf { 3 } }}$} \\
\hline Standard exposure & 14.88 & 4.75 \\
\hline Zero exposure & 8.38 & 3.75 \\
\hline Similar exposure & 33.5 & 15 \\
\hline
\end{tabular}

Table 3 shows the time weight average result of dust concentration of steel shot. The result of inhalable dust for standard exposure was $14.88 \mathrm{mg} / \mathrm{m}^{3}$ while zero exposure $8.38 \mathrm{mg} / \mathrm{m}^{3}$ and similar exposure $33.5 \mathrm{mg} / \mathrm{m}^{3}$. The standard exposure shows $4.75 \mathrm{mg} / \mathrm{m}^{3}$ for respirable dust while for zero exposure $3.75 \mathrm{mg} / \mathrm{m}^{3}$ and similar exposure $15 \mathrm{mg} / \mathrm{m}^{3}$.

Based on comparison made with the PEL of steel shot dust, the analysis show inhalable dust for steel shot show the value of dust concentration was exceeded the permissible exposure limit (PEL). For respirable dust also shown all type of analysis not exceeds the PEL except for similar exposure analysis.

According to the PNOC limit from USECHH 2000 Reg., for inhalable dust shown that all the analysis were exceed the limit except for zero exposure analysis. While for respirable dust; standard exposure, zero exposure and similar exposure exceed the limit in the regulations.

C. Energy Dispersive X-ray Spectrometry (EDS)

Energy Dispersive X-ray Spectrometry (EDS) was used to identify the composition of dust concentration. This analysis is only used the dust from inhalable dust sampler as the sample.

The analysis result for inhalable aluminium oxide shows the presence of several elements with the percentage of mass which are carbon (C) 11.66\%, aluminium (Al) 46.61\%, oxygen (O) $21.11 \%$, silicon (Si) 7.19\%, calcium (Ca) 4.97\%, titanium (Ti) 5.01\% and iron (Fe) 3.44\%. While for respirable shows the existing of carbon (C) 70.10\%, aluminium (Al) 6.11\%, oxygen (O) 10.46\%, silicon (Si) 3.35\%, calcium (Ca) 3.81\%, iron (Fe) $6.17 \%$.

Besides that, inhalable dust for steel shot shows existing of several elements which are iron (Fe) $29.87 \%$, carbon (C) 48.55\%, Silicon (Si) 17.96\%, lead (Pb) 3.61\% while for respirable are iron (Fe) 7.13\%, carbon (C) 65.85\%, Silicon (Si) 4.71\%, lead (Pb) $22.09 \%$ and manganese (Mn) $0.22 \%$.

The elements that exist in the media shows abrasive media is not only contains aluminium oxide and iron oxide but also containing of other elements. The entire element might be caused by external contaminant or blasting surfaces, the product material and maybe from paint or coating material.

\section{CONCLUSION}

The abrasive blasting is a process that generates high level of dust concentration which is very harmful to health of workers and people surrounding. Many ways that can be done to ensure that every blasting activity is controlled and stay in a safe condition. Based on the result, most analysis shows that the level of dust concentration has exceeded the permissible exposure limits during the blasting process. 
From the inhalable and respirable dust studies, three type of analysis has been used in the study different result. However most of the results shown the level of dust were exceed from permissible exposure limit.

The standard exposure is the best analysis to determine the level of exposure to the dust in this study because the sampling pump were operate for 8 hours during the analysis.

While comparing the result from similar exposure and zero exposure, it shown that it's very important to make sure during resting time all the workers need to avoid to expose the similar exposure or nearest to the working area. It will give a very big different in the level of dust exposure to the workers. Employer and workers also should plan and manage the duration of the exposure to the process for every worker to make sure the level of risks to the workers is always minimized.

From the result, it also suggested the best method to handle the blasting process is in the isolated area. This is importance to make sure the exposure to the high risk dust is control only for the blaster. Used of suitable PPE also compulsory for the workers in the area. Engineering control such as dust collector also the method can be implementing to the working area to control the hazardous dust.

The Energy Dispersive X-ray Spectrometry (EDS) proved that the presence of several elements in the dust that are harmful to health such as silica $(\mathrm{Si})$ and lead $(\mathrm{Pb})$.

In conclusion, the blasting process is a process that is very dangerous to the health of workers because it can release hazardous dust to human. Adequate control measure must be made a priority by the employer before abrasive blasting process is carried out.

\section{ACKNOWLEDGEMENT}

The authors would like to thank the Universiti Tun Hussein Onn Malaysia for supporting this research under short term grant (STG) U364.

\section{REFERENCES}

[1] N. Chillara, “Abrasive Blasting Process Optimization: Enhancing Productivity, and Reducing Consumption and Solid/Hazardous Wastes,” University of New Orleans, 2005.

[2] Centers for Disease Control and Prevention, "Preventing Silicosis and Deaths From Sandblasting,” DHHS Publ., no. 92, pp. 1-15, 1992.

[3] S. A. Anusree Basu, Farzana Haque Toma, Asma-ul-Hosna, Mehedi HAsan Lenin, Tunazzina Iqbal, Amirul Haque Amin, Kabir Hossein, Mohammad Elias, Shafia Pervin, "Deadly Denim: Sandblasting in the Bangladesh Garment Industry,” Bangladesh.

[4] M. Akgun, O. Araz, I. Akkurt, A. Eroglu, F. Alper, L. Saglam, A. Mirici, M. Gorguner, and B. Nemery, “An Epidemic of Silicosis Among Former Denim Sandblasters,” Eur. Respir. J., pp. 1-19, 2008.

[5] Parliament of Malaysia, Occupational Safety and Health (Use and Standards of Exposure of Chemical Hazardous to Health) Regulations. Malaysia, 2000.

[6] I. KTA-Tator, "Evaluation of Substitute Materials for Silica Sand in Abrasive Blasting,” Pittsburgh, PA, 1998.

[7] J. L. Goodier and G. C. R Lucas, E Boudreau, "Industrial Health and Safety Criteria for Abrasive Blast Cleaning Operations," Cincinnati, Ohio, 1974

[8] S. W. Australia, Abrasive Blasting: Code of Practice, no. October. Australia, 2012.

[9] D. of H. New Jersey, “Hazardous Substance Fact Sheet: Right to Know,” New Jersey, 2011.

[10] NIOSH, "Particulates Not Otherwise Regulated, Total 0500,” 1994.

[11] NIOSH, “Particulates Not Otherwise Regulated, Respirable 0600,” 1998.

\section{AUTHOR PROFILE}

Hanis Zakaria is working as instructor in Universiti Tun Hussein Onn Malaysia. His areas of research are in Occupational Safety and Health and Industrial Hygiene. 